\title{
Adobe's Mechanical Characterization in Ancient Constructions: The Case of Aveiro's Region
}

\author{
Tiago Martins ${ }^{1, a}$ and Humberto Varum ${ }^{1, b}$ \\ ${ }^{1}$ Civil Engineering Department, University of Aveiro, 3810-193 Aveiro, Portugal \\ aa19430@alunos.civil.ua.pt, ${ }^{\mathrm{b}} \mathrm{hvarum@civil.ua.pt}$
}

\begin{abstract}
Keywords: Adobe, Mechanical behaviour, Compressive strength, Tensile strength, Young modulus
\end{abstract}

\begin{abstract}
Adobe is commonly found in Aveiro's ancient constructions. Preservation and rehabilitation of those constructions, some of them with architectural and historical interest, has been forgotten for many years. As a result, in Aveiro region, the majority of existing constructions in adobe is structurally weak, and, in several cases, they are in the threshold of ruin. Rehabilitation and/or strengthening urge.

Despite some efforts has been made, a great difficulty for technicians working on the rehabilitation of these constructions relies on the lack of knowledge on adobe's mechanical behaviour. In fact, in order to properly describe the structural behaviour of those constructions, there is a need to investigate the mechanical behaviour of adobe. Hence, this paper is based on a study intended to characterise the behaviour of adobe brick units. Specimens were prepared from selected representative constructions of the Aveiro region. The prepared specimens were tested in order to evaluate their mechanical behaviour in compression and tension.
\end{abstract}

\section{Introduction}

Adobe was for millenniums the main construction material in the world. Many ancient buildings were built with this material and some of them are still in good conditions to be used and appreciated as important constructions of architectural interest, which attests the considerable mechanical characteristics of these materials and structures, as per example the constructions in the south of Spain [2].

In Aveiro's region, it is still common to find ancient adobe buildings. In this ancient region, known by the time as Gandaresa, adobe was the principal structural material for the great majority of buildings made until about the middle of the previous century [3].

However, this important legacy was forgotten since the arrival of other structural materials, such as concrete. It was the beginning of a progressive decay in adobe construction. Even in the existing constructions, the preservation and rehabilitation of those structures have been neglected. Consequently, nowadays, adobe constructions are structurally weak, and, several of them, ruined. For that reason, it is essential the rehabilitation and/or strengthening of those structures. Despite some efforts that are being made by researchers and technicians working in the rehabilitation field, the lack of knowledge on adobe's mechanical behaviour still is the main obstacle in the preservation of those constructions. In fact, in order to describe properly the structural behaviour of those constructions, there is a need to investigate the mechanical behaviour of adobe. Therefore, the main purpose of the study presented in this paper is to characterise the mechanical behaviour of adobe blocks.

\section{Testing procedure}

The great variety of adobe in terms of dimensions, and the immeasurable different components used on its production, makes it a material with an enormous variability in terms of mechanical 
properties. Considering this difficulty, for the mechanical behaviour characterisation, it was selected a set of specimens representative of the adobe traditionally used in Aveiro's region.

Cylindrical specimens were extracted from three different constructions in adobe. One series of specimens were extracted from a small (Fig. 1) house and the other two series were extracted from two walls (Fig. 2 and 3). The constitution of these three adobe's are significantly different, and consequently the strength also reflects that, as will be presented in the test results.

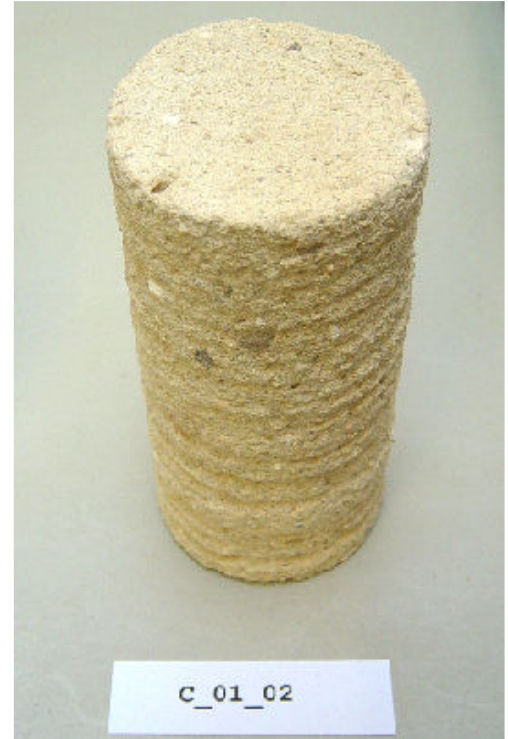

Fig. 1 - House specimen

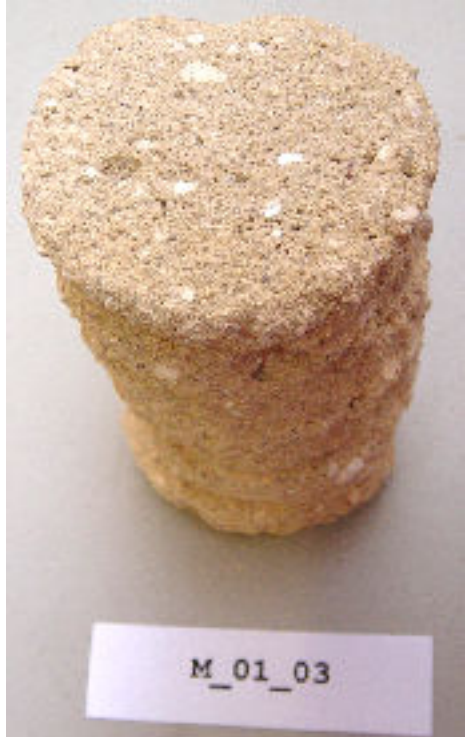

Fig. 2 - Wall 1 specimen

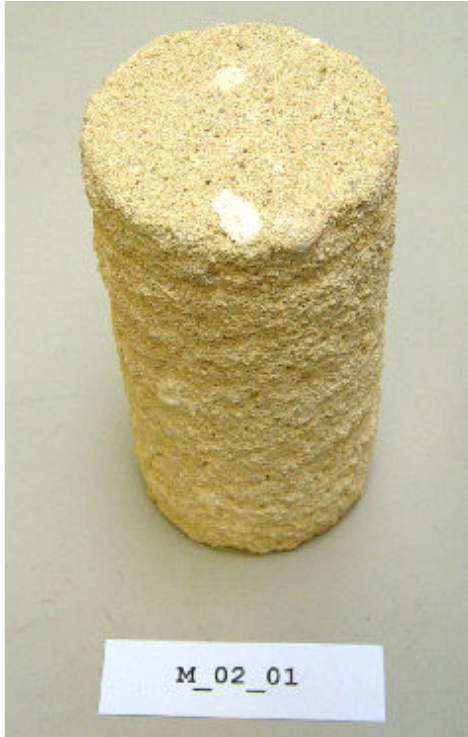

Fig. 3 - Wall 2 specimen

A total of 16 cylindrical specimens were drilled from adobe brick units, to study their mechanical behaviour. The extracted specimens were prepared (regularization of the bases, normalization of the dimensions), in order to be tested in similar conditions of orthogonality and size (about $170 \mathrm{~mm}$ height and $85 \mathrm{~mm}$ diameter).

The specimens were divided in two groups, one to perform the compression tests (Fig. 4), and the other for the diametral compression tests (Fig. 5).

Due to adobe standard mechanical tests' inexistence, it were followed the RILEM technical recommendations for concrete specimen tests [4], to evaluate the compressive and tensile strength of the adobe specimens. The compressive strength was determined from the failure compression load divided by the specimen area resisting to the load and reported in units $\left[\mathrm{N} / \mathrm{mm}^{2}\right]$, as described in RILEM CPC4. The compressive strength is commonly used in the safety assessment and design of constructions.

The diametral compression test was used to determine the tensile strength of the adobe. A compressive load was applied across the diameter of the specimen creating a nearly uniform state of tension across a vertical plane. Tensile strength of the specimen was measured by increasing the compressive load until the specimen fails in tension. The tensile strength, as described in RILEM CPC6 [4], is given by:

$\sigma=2 \mathrm{~F} /(\pi \mathrm{DH})\left[\mathrm{N} / \mathrm{mm}^{2}\right]$

where:

$\mathrm{F}$ is the load applied [N];

$\mathrm{D}$ is the diameter of the specimen $[\mathrm{mm}]$; and,

$\mathrm{H}$ is the height of the specimen [mm]. 


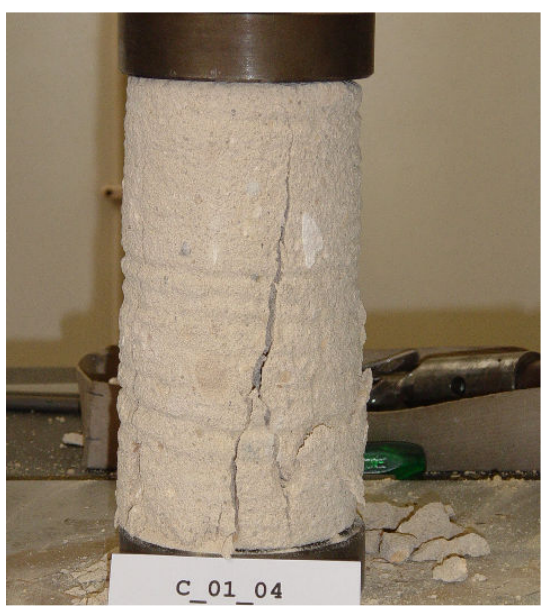

Fig. 4 - Compression tests

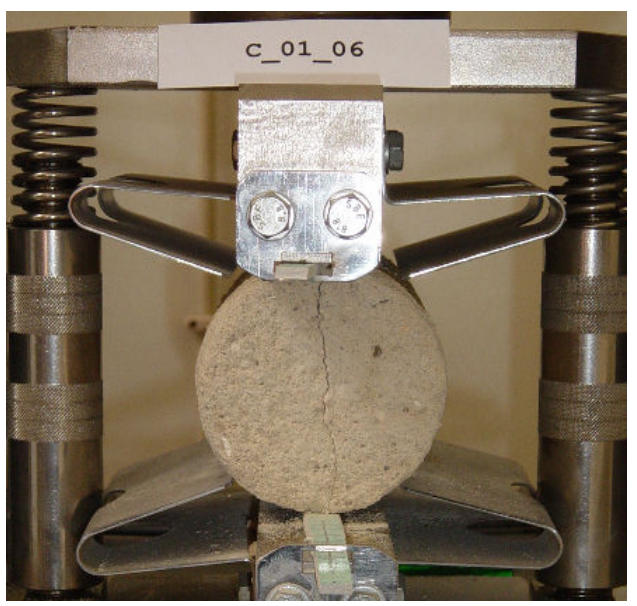

Fig. 5 - Diametral compression tests

\section{Analysis and discussion of the test results}

In this section are presented the stress-strain behaviour curves obtained, for the compression and diametral compression tests (Fig. 6 to 9). The obtained results are discussed.

From the stress-strain behaviour curves, it was registered the peak strength (compressive strength and tensile strength, derived from the diametral compression test). The Young modulus was also estimated from the stress-strain curves for low levels of stress (between $10 \%$ and $20 \%$ of the specimen strength). In Table 1 are summarised the results obtained for each tested specimen. For the specimen M_01_05, the obtained curve was inconclusive, so this result was not included in the summary table.

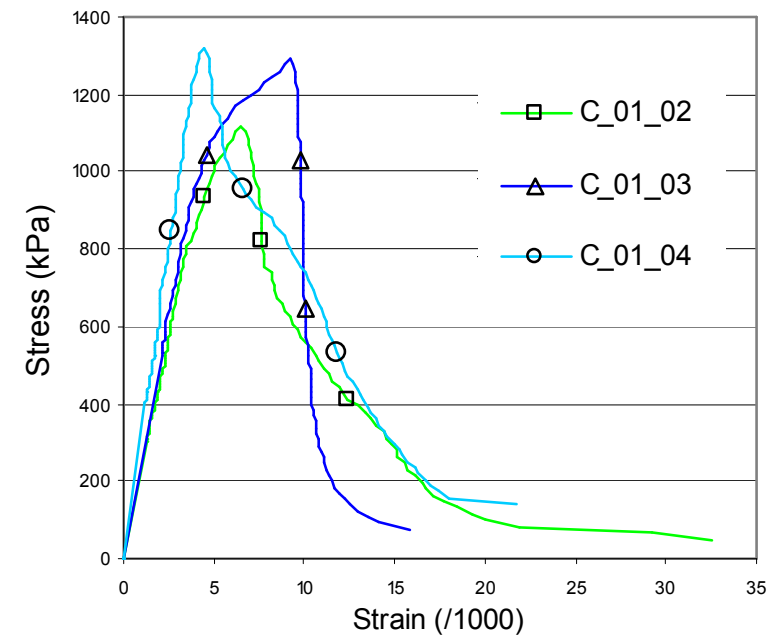

Fig. 6-Compression test - House

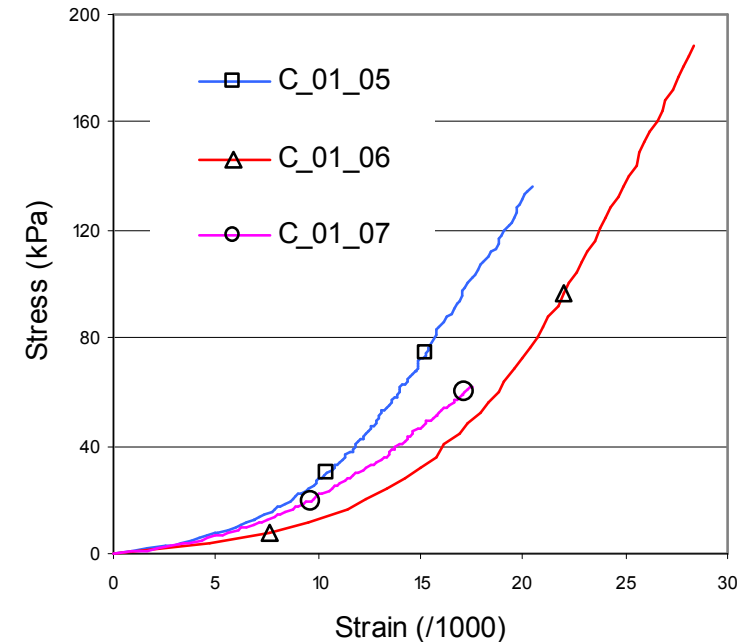

Fig. 7 - Diametral compression test - House 


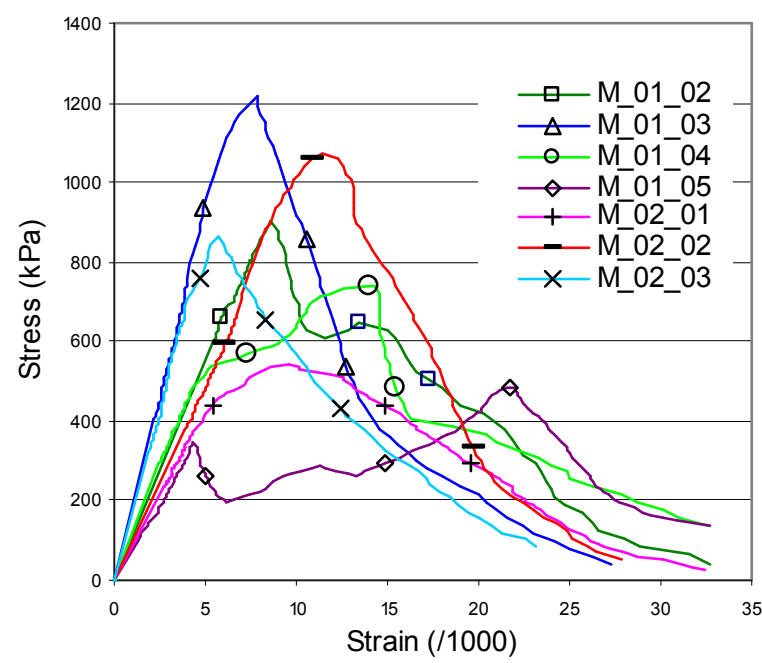

Fig. 8 - Compression test - Walls

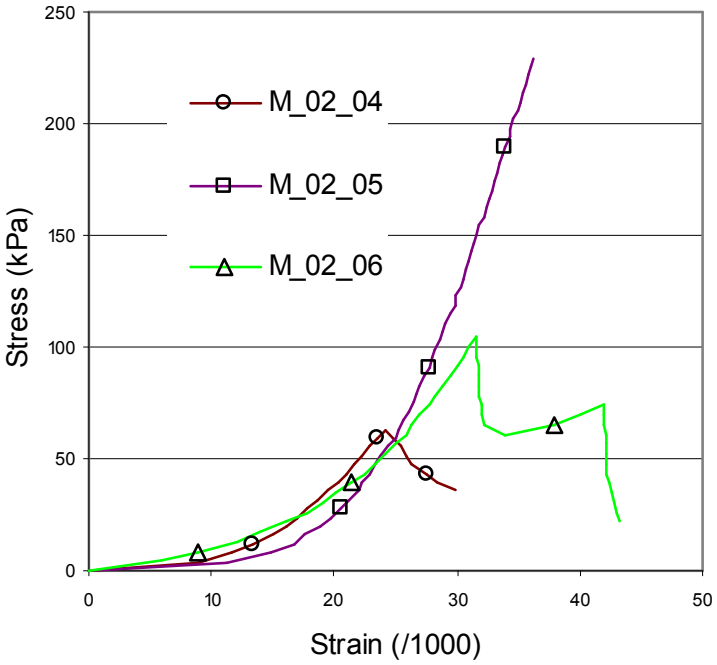

Fig. 9 - Diametral compression test - Walls

Table $1-$ Summary table of the test results

\begin{tabular}{|c|c|c|c|c|c|}
\hline \multirow[b]{2}{*}{ Specimer } & & \multicolumn{4}{|c|}{ Mechanical properties } \\
\hline & & $\begin{array}{c}\text { Young modulus } \\
{[\mathrm{MPa}]}\end{array}$ & $\begin{array}{c}\text { Compressive } \\
\text { strength }[\mathrm{kPa}]\end{array}$ & $\begin{array}{c}\text { Strain at peak } \\
\text { strength }[1 / 1000]\end{array}$ & $\begin{array}{c}\text { Tensile strength } \\
{[\mathrm{kPa}]}\end{array}$ \\
\hline \multirow{7}{*}{ House } & C_01_02 & 230.0 & 1118.0 & 6.5 & -- \\
\hline & C_01_03 & 250.0 & 1291.5 & 9.2 & -- \\
\hline & C_01_04 & 340.0 & 1320.4 & 4.7 & -- \\
\hline & C_01_05 & -- & -- & -- & 136.1 \\
\hline & C_01_06 & -- & -- & -- & 188.5 \\
\hline & C_01_07 & -- & -- & -- & 62.2 \\
\hline & Average & 273.3 & 1243.3 & 6.8 & 128.9 \\
\hline \multirow{4}{*}{ Wall 1} & M_01_02 & 110.0 & 899.9 & 8.5 & -- \\
\hline & M_01_03 & 185.0 & 1213.6 & 7.8 & -- \\
\hline & M_01_04 & 120.0 & 737.4 & -- & -- \\
\hline & Average & 138.3 & 950.3 & 8.2 & -- \\
\hline \multirow{7}{*}{ Wall 2} & M_02_01 & 85.0 & 542.8 & 9.5 & - \\
\hline & M_02_02 & 97.0 & 1075.0 & 11.5 & -- \\
\hline & M_02_03 & 170.0 & 860.8 & 5.7 & -- \\
\hline & M_02_04 & -- & -- & -- & 63.2 \\
\hline & M_02_05 & -- & -- & -- & 229.6 \\
\hline & M_02_06 & -- & -- & -- & 104.4 \\
\hline & Average & 117.3 & 826.2 & 8.9 & 132.4 \\
\hline
\end{tabular}

In Fig. 10 are plotted, for each test series, the average strength obtained from the compression test and from the diametral compression test.

In an attempt to find a correlation between the two strengths the obtained results for Aveiro's adobes were compared with the results presented in the study of Vargas et al. [1]. In this work, soils from six zones of Peru where adobe construction is traditional were selected, namely from Cajamarca, Cuzco, Huancayo, Huaraz, Pisco and PUC. It is underlined that in these zones the adobe is manufactured as a mixture of soil and water, without any additives. The soil samples were collected, prepared and tested to estimate the mechanical strength of the traditional adobe. For the mechanical characterization of these adobe samples, it was evaluated the compressive and tensile strength. In the graphic of Fig. 10, are confronted the mechanical strength results from the Aveiro 
and Peru adobes's. The adobe from Aveiro has higher strength (compressive and tensile). It is possible to perceive also a tendency for a correlation between the compressive and tensile strength.

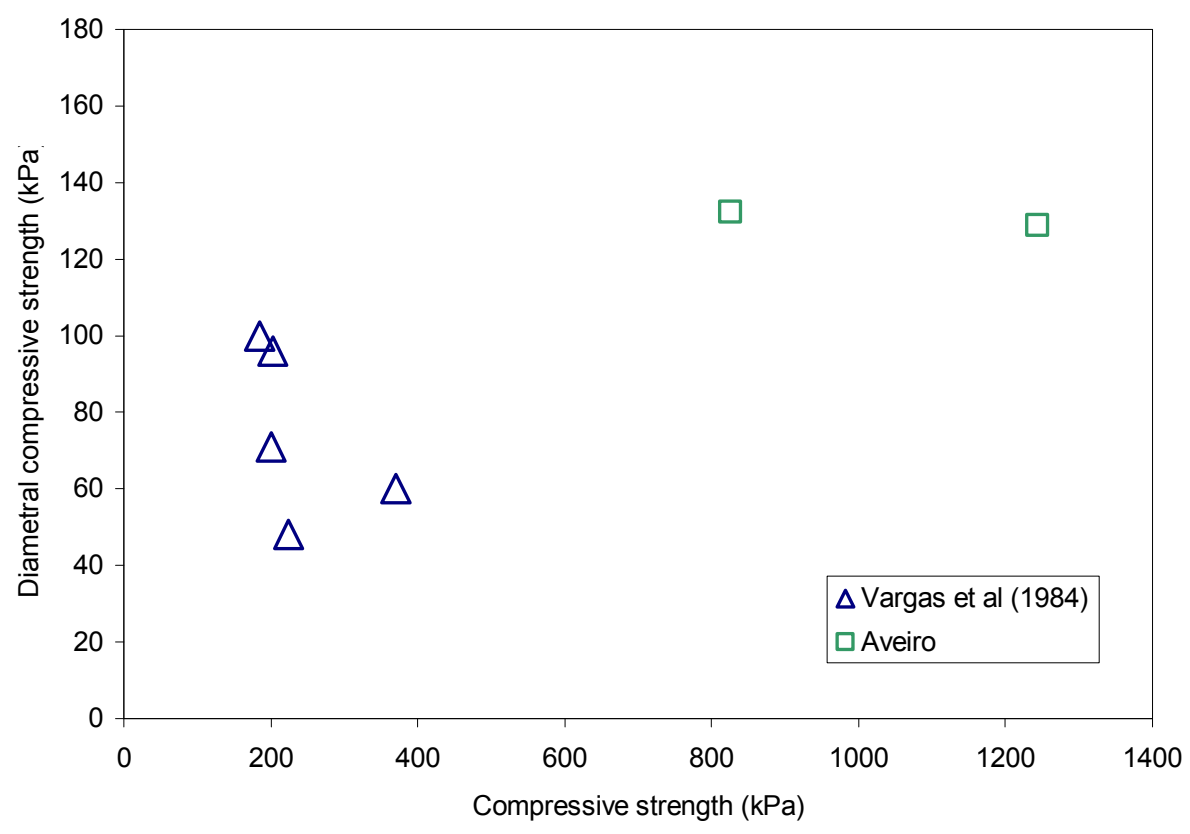

Fig. 10 - Compressive strength versus Diametral compressive strength

\section{Conclusions}

The main objective of this work was to estimate the strength of adobe and, to characterize its mechanical behaviour, in terms of behaviour curves.

The results obtained from the compression tests show significant compressive strength (0.5-1.2 $\mathrm{MPa}$ ). For the tensile strength was obtained approximately $20 \%$ of the corresponding compressive strength. Comparing the results obtained for the walls and house specimens, it can be observed higher strength and stiffness (Young's modulus) values for the specimens' extracted form the house. The walls specimens' presented a higher heterogeneity, and consequently variability in the results. Attending to the great variability in the constitution and dimensions of the adobe blocks, a more exhaustive testing campaign would be required. Therefore, it was already started a complementary testing campaign in order to better represent the existing adobe construction in Aveiro's region.

Finally, an important work has been already started in order to understand the influence of the adobe's granulometric composition in the mechanical properties (strength and stiffness) heterogeneity.

\section{Acknowledgments}

The authors would like to acknowledge the Ceramics and Glass Department for its technical support, who made possible the tests carried out.

\section{References}

[1] J. Vargas; J. Bariola; M. Blondet and K. Mehta (1984) - Seismic strength of adobe masonry Tutorials on Earthquake-Resistant Housing Construction Practices - Adobe tutorials - Earthquake Engineering Research Institute - U.S. Agency for International Development (AID) Research Project DI-84-01.

[2] J.R. Arango González, Uniaxial deformation-stress behaviour of the rammed-earth of the Alcazaba Cadima, Materials and Structures, University of Granada (Spain), 1999.

[3] E. Veiga Oliveira and F. Galhano, Arquitectura Tradicional Portuguesa, Portugal de perto, Publicações D. Quixote, Lisboa, 1992.

[4] RILEM Technical Recommendations for the Testing and Use of Construction Materials (1994),

E \& FN Spon, London, England. 